\title{
Adding Clonidine to Ropivacaine in Brachial Plexus Block for Upper Limb Surgeries: Study of Hemodynamic Variables
}

\author{
Virupakshamma ${ }^{1}$, Ajay Basarigidad \\ ${ }^{1}$ Senior Resident, Department of Anesthesiology, Gadag Institute of Medical sciences, Gadag, Karnataka.
}

\section{Abstract}

Background: Ropivacaine is a long acting amide local anaesthetic agent. It was first synthesized in 1957 along with bupivacaine and mepivacaine. It is a pure S-enantiomer while bupivacaine is a racemic mixture. Ropivacaine causes reversible inhibition of sodium ion influx, and thereby blocks impulse conduction in nerve fibres. This action is potentiated by dose-dependent inhibition of potassium channels. Subjects and Methods: This study was conducted on 60 patients undergoing upper limb surgeries aged between 18 to 55 years under supraclavicular block. Informed written consent was taken. Result values were recorded using a preset proforma. Results: There were 24 patients in Group R and 23 patients in Group RC belonging to ASA Grade I, and 6 patients in Group R and 7 patients in Group RC belonging to ASA Grade II which was considered statistically not significant. Conclusion: The combination produces improved analgesia, resulting in a prolonged effect and stable hemodynamics.

Keywords: Clonidine, Ropivacaine, Hemodynamic Variables.

Corresponding Author: Dr. Ajay Basarigidad, Senior Resident, Department of Anesthesiology, Gadag Institute of Medical sciences, Gadag, Karnataka.

Received: February 2019

Accepted: February 2019

\section{Introduction}

Knowledge of formation of brachial plexus and its ultimate cutaneous and muscular distribution is absolutely essential to the intelligent and effective use of brachial plexus anaesthesia for upper limb surgeries. Close familiarity with the vascular, muscular and fascial relationships of the plexus is equally essential to the mastery of various techniques, for it is these perineural structures which serve as the landmark by which needle may accurately locate the plexus percutaneously. ${ }^{[1]}$

In its course from intervertebral foramina to the upper arm, the fibres are composed consecutively of roots ,trunks, divisions, cords and terminal nerves.

In 1911-1912, KULENKAMPFF described the first percutaneous supraclavicular approach. He pointed out that above the clavicle the plexus lies under the skin as it passes over the first rib and accessible to a percutaneous technique. The midpoint of the clavicle and subclavian artery provided a constant landmark. Most frequently at the point where external jugular vein intersects the clavicle. He performed his first attempt on himself and used $5 \mathrm{ml}$ of Novocaine, later he increased it to $10 \mathrm{ml}$ and was able to obtain complete anaesthesia. Direction of the needle was backwards, inwards and downwards. He emphasized that purpose of the technique was not to hit the rib but to find the trunks by eliciting paraesthesia. He said the rib just prevented pleural penetration. He used $4 \mathrm{~cm}$ needle. ${ }^{[2]}$
LABAT in 1922, advocated an injection at three separate points which failed to elicit paraesthesia by Kulenkampff's method. First injection beneath the deep fascia in the direction of the first rib, second towards the chassaignac's tubercle and the third towards the lateral margin of the first rib behind the clavicle (5 $\mathrm{ml}$ with each injection). ${ }^{[3]}$

In 1926, LIVINGSTON, carried out Kulenkampffs technique without the production of paraesthesia as soon as the deep cervical fascia had been penetrated. $30 \mathrm{ml}$ of $2 \%$ procaine was injected. He wrote that the plexus and the artery are separated from the surrounding structures by a fascial investment. ${ }^{[4]}$

In 1940, PATRICK chose to lay down a "wall of anaesthetic" through which the plexus must pass in its course over the first rib, where $60-70 \mathrm{ml}$ of solution was being injected during 5-6 insertions. This technique became the "standard technique" of supraclavicular block, subsequently referred to by many as the "classical supraclavicular technique". ${ }^{[5]}$

In 1942 KNIGHT modified Patrick's technique by making the three injections through three separate needle insertion, parallel to one another. For the first time he utilized a directly caudal direction of needle insertion. ${ }^{[6]}$

In 1944, MURPHEY used a single injection technique and used lateral border of anterior scalene muscle as the landmark and direction of needle insertion caudal as with Knight's technique, not medial or dorsal, as with most other techniques. ${ }^{\text {[7] }}$

In 1949, BONICA and MOORE utilized Kulenkampffs and Patrick's techniques and developed a technique where it 
begins with utilizing the classical landmarks and direction of needle insertion and demands a definite paraesthesia prior to first injection. Then continue as Patrick's technique and lay down a wall of anaesthetic solution by "walking the rib" and make multiple injections during each withdrawal of the needle. This was used over subsequent twenty years. ${ }^{[8]}$

In 1958, LOOKMAN fully realised the potential of the sheath, who like Livingston realised on the fascial investment of the plexus. He carefully dissected the plexus and said that plexus lies in a closed compartment. He said this space lies between the anterior and middle scalene muscles and is pyramidal in shape, with its apex pointing upwards and medially towards the exit of the fourth cervical nerve. He did not verify the needle's proper placement within the space before injection. He admitted the tendency for the point of the needle to pass too posteriorly and hence to come to be within the substance of (or even behind) the middle scalene muscle. ${ }^{[9]}$

FORTIN and TREMBLAY advocated the use of a short needle, which was long enough to reach the plexus but too short to reach the lung, in a attempt to minimize the threat of pneumothorax.

In 1964 WINNIE after numerous anatomical dissections showed that the relation of the plexus and the subclavian artery to the midpoint of the first rib is not constant. He showed that there is a constant relationship between the anterior and middle scalene muscles, the plexus and the first rib. The plexus between the two scalene muscles always insert on the first rib. He inserted needle between the two muscles, in the direction of the space between them. Once a paraesthesia is obtained, a single injection is made into the space. $^{[10]}$

Ropivacaine is a long acting amide local anaesthetic agent. It was first synthesised in 1957 along with bupivacaine and mepivacaine. It is a pure $\mathrm{S}$-enantiomer while bupivacaine is a racemic mixture.

Ropivacaine causes reversible inhibition of sodium ion influx, and thereby blocks impulse conduction in nerve fibres. This action is potentiated by dose-dependent inhibition of potassium channels. Ropivacaine is less lipophilic than bupivacaine and is less likely to penetrate large myelinated motor fibres; therefore it has selective action on the pain transmitting $\mathrm{A}$ delta and $\mathrm{C}$ nerves rather than A- beta fibres, which are involved in motor function. ${ }^{[1]}$ Ropivacaine is less lipophilic than bupivacaine and that, together with stereoselective properties contributes to ropivacaine having a significantly higher threshold for cardiotoxicity and CNS toxicity than bupivacaine. ${ }^{[12]}$

The CNS effects occurred earlier than cardiotoxic symptoms during an intravenous infusion of local anaesthetic $(10 \mathrm{mg} / \mathrm{kg})$ in human volunteers and the infusion was stopped at this point. Significant changes in cardiac function involving the contractility, conduction time and QRS width occurred and the increase in QRS width was found to be significantly smaller with Ropivacaine than Bupivacaine.

\section{Subjects and Methods}

This study was conducted on 60 patients undergoing upper limb surgeries aged between 18 to 55 years under

supraclavicular block.

Informed written consent was taken. Result values were recorded using a preset proforma.

Inclusion criteria:

- Patients with ASA Class I \& II

- Patients aged between 18 to 55 years.

- Patients with SBP 100-139mm of Hg.

- Patients with DBP $60-89 \mathrm{~mm}$ of $\mathrm{Hg}$.

\section{Exclusion criteria:}

- Patients belonging to ASA Class III \& IV.

- Known cause of hypersensitive reaction to Clonidine.

- Patients with medical complications like severe anemia, severe hypovolemia, shock, and septicemia.

- Patients with abnormal BT, CT or on anticoagulant therapy.

- Local infection at the site of proposed puncture for supraclavicular block.

\section{Results}

Sixty ASA I and II of either sex aged between 18-55 years, posted for upper limb surgeries under supraclavicular brachial plexus block were selected for the study. The study was undertaken to evaluate the efficacy of Clonidine $(150 \mu \mathrm{g})$ as adjuvant to Ropivacaine $(0.75 \%)$ in comparison with plain Ropivacaine $(0.75 \%)$ for brachial plexus block by supraclavicular approach.

Table 1: Age distribution of patients studied.
\begin{tabular}{|l|l|l|l|l|}
\hline \multirow{2}{*}{ Age in years } & Ropivacaine & Ropivacaine+Clonidine \\
\cline { 2 - 5 } & No & $\%$ & No & $\%$ \\
\hline$<20$ & 2 & 6.7 & 4 & 13.3 \\
\hline $20-30$ & 10 & 33.3 & 12 & 40.0 \\
\hline $31-40$ & 11 & 36.7 & 4 & 13.3 \\
\hline $41-50$ & 7 & 23.3 & 8 & 26.7 \\
\hline $51-60$ & 0 & 0.0 & 2 & 6.7 \\
\hline Total & 30 & 100.0 & 30 & 100.0 \\
\hline Mean \pm SD & $33.87 \pm 9.86$ & $33.67 \pm 11.59$ \\
\hline
\end{tabular}

Samples are age matched with $\mathrm{p}$ values of 0.943

The minimum age of the patient was 18 years and the maximum age was 55 years. The mean age of the patients in group R was $33.87 \pm 9.86$ and in group RC was $33.67 \pm 11.59$ years. Age incidences between two groups were comparable.

Table 2: ASA Grade distribution in two groups of patients studied

\begin{tabular}{|l|l|l|l|l|}
\hline \multirow{2}{*}{ Age in years } & \multicolumn{2}{|l|}{ Group R } & \multicolumn{2}{l|}{ Group RC } \\
\cline { 2 - 5 } & No & \% & No & \% \\
\hline Grade I & 24 & 80.0 & 23 & 76.7 \\
\hline Grade II & 6 & 20.0 & 7 & 23.3 \\
\hline Total & 30 & 100.0 & 30 & 100.0 \\
\hline
\end{tabular}

$\mathrm{P}=0.754$, Not significant, Chi-Square test

Table 3: Pulse rate (beats/min)

\begin{tabular}{|l|l|l|l|}
\hline $\begin{array}{l}\text { Pulse rate } \\
\text { (beats/min) }\end{array}$ & Group R & Group RC & P value \\
\hline $0 \mathrm{~min}$ & $76.10 \pm 8.15$ & $77.47 \pm 7.83$ & 0.510 \\
\hline $5 \mathrm{~min}$ & $76.03 \pm 7.86$ & $77.53 \pm 7.42$ & 0.450 \\
\hline $15 \mathrm{~min}$ & $75.97 \pm 7.84$ & $77.47 \pm 7.30$ & 0.446 \\
\hline $30 \mathrm{~min}$ & $76.07 \pm 8.07$ & $76.70 \pm 7.84$ & 0.759 \\
\hline $60 \mathrm{~min}$ & $76.37 \pm 7.69$ & $77.63 \pm 7.92$ & 0.532 \\
\hline $2 \mathrm{hrs}$ & $76.13 \pm 7.94$ & $77.10 \pm 7.92$ & 0.639 \\
\hline $6 \mathrm{hrs}$ & $76.17 \pm 8.18$ & $77.53 \pm 7.19$ & 0.495 \\
\hline $12 \mathrm{hrs}$ & $76.20 \pm 8.12$ & $77.77 \pm 7.72$ & 0.447 \\
\hline $24 \mathrm{hrs}$ & $76.27 \pm 8.27$ & $77.87 \pm 7.25$ & 0.429 \\
\hline
\end{tabular}


There were 24 patients in Group R and 23 patients in Group $\mathrm{RC}$ belonging toASA Grade I , and 6 patients in Group R and 7 patients in Group RC belonging to ASA Grade II which was considered statistically not significant.

Pulse rate, systolic $\mathrm{BP}$, diastolic $\mathrm{BP}, \mathrm{O} 2$ saturation was recorded at $0 \mathrm{~min}, 5 \mathrm{~min}, 15 \mathrm{~min}, 30 \mathrm{~min}, 60 \mathrm{~min}, 2$ hours, 6 hours, 12 hours, 24 hours.

In group $\mathrm{R}$, the mean pulse rate ranged from $75 \pm 7.84$ to $76 \pm$ 7.69 beats / min. In group $\mathrm{RC}$, the mean pulse rate ranged from $76 \pm 7.84$ to $77 \pm 7.25$ beats / min. The statistical analysis by student ${ }^{\text {ee }}$ unpaired ,te test showed that there was no significant difference in pulse rate between the two groups $(\mathrm{P}>0.05)$.

Table 4: Systolic blood pressure (mm of Hg)
\begin{tabular}{|l|l|l|l|}
\hline $\begin{array}{l}\text { Systolic blood } \\
\text { pressure } \\
(\mathbf{m m} \text { Hg) }\end{array}$ & Group R & Group RC & P value \\
\hline $0 \mathrm{~min}$ & $117.80 \pm 9.52$ & $117.40 \pm 9.51$ & 0.871 \\
\hline $5 \mathrm{~min}$ & $117.73 \pm 9.26$ & $117.13 \pm 9.68$ & 0.807 \\
\hline $15 \mathrm{~min}$ & $117.53 \pm 9.15$ & $117.33 \pm 9.86$ & 0.935 \\
\hline $30 \mathrm{~min}$ & $117.80 \pm 9.44$ & $117.20 \pm 9.64$ & 0.808 \\
\hline $60 \mathrm{~min}$ & $117.40 \pm 9.53$ & $117.40 \pm 9.57$ & 1.000 \\
\hline $2 \mathrm{hrs}$ & $117.60 \pm 9.49$ & $117.27 \pm 9.37$ & 0.892 \\
\hline $6 \mathrm{hrs}$ & $117.73 \pm 9.51$ & $117.33 \pm 9.46$ & 0.871 \\
\hline $12 \mathrm{hrs}$ & $117.87 \pm 9.39$ & $117.27 \pm 9.72$ & 0.809 \\
\hline $24 \mathrm{hrs}$ & $117.73 \pm 9.41$ & $117.47 \pm 9.63$ & 0.914 \\
\hline
\end{tabular}

In group $\mathrm{R}$, the mean systolic blood pressure ranged from $117.40 \pm 9.53$ to $117.80 \pm 9.52 \mathrm{~mm}$ of $\mathrm{Hg}$. In group $\mathrm{RC}$, the mean systolic blood pressure ranged from $117.13 \pm 9.68$ to $117.47 \pm 9.63 \mathrm{~mm}$ of $\mathrm{Hg}$. The statistical analysis by unpaired student's $\mathrm{t}$ test showed that there was no significant difference in systolic blood pressure between the two groups $(\mathrm{P}>0.05)$.

Table 5: Comparison of Diastolic blood pressure $(\mathrm{mm} \mathrm{Hg})$ in two groups of patients studied

\begin{tabular}{|l|l|l|l|}
\hline $\begin{array}{l}\text { Diastolic } \\
\text { blood } \\
\text { pressure (mm } \\
\text { Hg) }\end{array}$ & Group R & Group RC & P value \\
\hline $0 \mathrm{~min}$ & $74.27 \pm 6.12$ & $74.33 \pm 5.68$ & 0.965 \\
\hline $5 \mathrm{~min}$ & $74.60 \pm 6.08$ & $74.27 \pm 5.45$ & 0.824 \\
\hline $15 \mathrm{~min}$ & $74.53 \pm 6.03$ & $74.53 \pm 5.87$ & 1.000 \\
\hline $30 \mathrm{~min}$ & $74.47 \pm 5.67$ & $74.27 \pm 5.98$ & 0.895 \\
\hline $60 \mathrm{~min}$ & $74.40 \pm 5.67$ & $74.27 \pm 5.82$ & 0.929 \\
\hline $2 \mathrm{hrs}$ & $74.27 \pm 5.94$ & $74.20 \pm 5.67$ & 0.965 \\
\hline $6 \mathrm{hrs}$ & $74.2 \pm 5.86$ & $74.00 \pm 5.68$ & 0.894 \\
\hline $12 \mathrm{hrs}$ & $74.13 \pm 6.06$ & $74.60 \pm 5.49$ & 0.756 \\
\hline $24 \mathrm{hrs}$ & $74.00 \pm 6.17$ & $74.60 \pm 5.10$ & 0.683 \\
\hline
\end{tabular}

Table 6: Comparison of Oxygen saturation (\%)in two groups of patients studied

patients studied
\begin{tabular}{|l|l|l|l|}
\hline $\begin{array}{l}\text { Oxygen } \\
\text { saturation } \\
(\%)\end{array}$ & Group I & Group II & P value \\
\hline $0 \mathrm{~min}$ & $98.73 \pm 0.45$ & $98.67 \pm 0.48$ & 0.581 \\
\hline $5 \mathrm{~min}$ & $98.70 \pm 0.47$ & $98.77 \pm 0.43$ & 0.567 \\
\hline $15 \mathrm{~min}$ & $98.73 \pm 0.45$ & $98.70 \pm 0.47$ & 0.779 \\
\hline $30 \mathrm{~min}$ & $98.77 \pm 0.43$ & $98.53 \pm 0.51$ & $0.060+$ \\
\hline $60 \mathrm{~min}$ & $98.77 \pm 0.43$ & $98.67 \pm 0.48$ & 0.399 \\
\hline $2 \mathrm{hrs}$ & $98.53 \pm 0.51$ & $98.77 \pm 0.43$ & $0.060+$ \\
\hline $6 \mathrm{hrs}$ & $98.60 \pm 0.50$ & $98.67 \pm 0.48$ & 0.599 \\
\hline $12 \mathrm{hrs}$ & $98.63 \pm 0.49$ & $98.63 \pm 0.49$ & 1.000 \\
\hline $24 \mathrm{hrs}$ & $98.63 \pm 0.49$ & $98.77 \pm 0.43$ & 0.267 \\
\hline
\end{tabular}

In group $\mathrm{R}$, the mean diastolic blood pressure ranged from $74 \pm 6.17$ to $74.60 \pm 6.08 \mathrm{~mm}$ of $\mathrm{Hg}$. In group $\mathrm{RC}$, the mean diastolic blood pressure ranged from $74 \pm 5.68$ to $74.60 \pm$ $5.49 \mathrm{~mm}$ of $\mathrm{Hg}$. The statistical analysis by studente's unpaired "t" test showed that there was no significant difference in diastolic blood pressure between the two groups $(\mathrm{P}>0.05)$. In group $\mathrm{R}$, the mean $\mathrm{O}_{2}$ saturation ranged from $98 \pm 0.5 \%$ to $99 \pm 0.57 \%$. In group $\mathrm{RC}$, the mean $\mathrm{O}_{2}$ saturation ranged from $98 \pm 0.5 \%$. The statistical analysis by students unpaired , $\mathrm{t}^{\text {ee }}$ test showed that there was no significant difference in $\mathrm{O}_{2}$ saturation between the two groups $(\mathrm{P}>0.05)$.

\section{Discussion}

Brachial plexus block provides postoperative analgesia of short duration, even when a long-acting local anaesthetic like Ropivacaine is used alone. Various adjuvant drugs like Opioids, Midazolam, Neostigmine and Hyaluronidase have been evaluated in conjunction with local anaesthetics to prolong the period of analgesia, ${ }^{[13]}$ but they were found to be either ineffective or to produce an unacceptably high incidence of adverse effects. Clonidine is known to produce antinociception and to enhance the effect of local anaesthetic when administered intrathecally and epidurally. Clonidine produces this effect by its action on Alpha 2 adrenergic receptors found in peripheral nerves.

Mehdi Trifa et al, ${ }^{[1]}$ added clonidine to ropivacaine in axillary plexus block in children undergoing upper limb surgery and found that addition of clonidine increased the time to first analgesia request. Clonidine produces this additive effect on local anaesthetics by its action on the presynaptic alpha-2 receptor complexes present on peripheral nerves. Murphy et al, ${ }^{[11]}$ analysed the usefulness of a variety of adjuvants including clonidine added to local anaesthetics for brachial plexus block and concluded that clonidine in doses upto $150 \mathrm{~g}$ increased the duration of postoperative analgesia with minimal adverse effects. Danelli $\mathrm{G}$ et al, ${ }^{[15]}$ evaluated the effects of adding clonidine to ropiivacaine for superficial cervical plexus block in patients undergoing elective carotid endarterectomy and found that adding clonidine to ropivacaine shortened the onset time and improved the quality of surgical anaesthesia. Casati et al, ${ }^{[16]}$ added clonidine to ropivacaine in sciatic femoral nerve block for foot surgery and found that addition of clonidine to $0.75 \%$ Ropivacaine prolongs the duration of postoperative analgesia with only a slight and short lived increase in degree of sedation and no hemodynamic adverse effects.

The prolonged analgesia in Group RC could be due to the action of Clonidine by inhibiting action potential of $\mathrm{A} \& \mathrm{C}$ fibers in peripheral nerves as demonstrated by Gaumann et al. ${ }^{[17]}$ Many authors favor the hypothesis that Clonidine exerts its local anesthetic-prolonging effect directly on nerve fiber, as a result of complex interaction between Clonidine and axonal ion channels or receptors. Masuki et al. ${ }^{[18]}$, suggested Clonidine may produce local vasoconstriction resulting in a delayed absorption of local anesthetic and block prolongation. Butterworth et al. ${ }^{[19]}$ found Clonidine to produce tonic and phasic block of nerve conduction in rat sciatic nerve fibers by directly binding to Alpha-2 adrenergic 
receptors on presynaptic peripheral nerves to modify neuronal excitability.

We studied Clonidine at a dose of $150 \mu \mathrm{g}$ as others have used the same dosage in peripheral nerve block without any significant adverse effects. El Saied et al showed that addition of $150 \mu \mathrm{g}$ of clonidine to ropivacaine for brachial plexus blockade prolongs motor and sensory block and analgesia, without an increased incidence of side effects. Bernard et al evaluated effects of adding 30-300 mcg Clonidine to local anesthetic for brachial plexus block and found it is hemodynamically safe upto $150 \mathrm{mcg}$. A similar observations were made by Singelyn et al. ${ }^{[19]}$ who suggested $0.5-1 \mathrm{mcg} / \mathrm{kg}$ of clonidine satisfactorily prolongs the analgesia of local anesthetic in peripheral nerve blocks without undue hemodynamic side effects of alpha-2 agonism.

\section{Conclusion}

No significant difference in haemodynamic variables i.e., pulse rate, systolic BP, diastolic BP and $\mathrm{O} 2$ saturation.

\section{References}

1. Morgan GE Jr, Mikhail MS, Murray MJ. Clinical Anaesthesiology, 4th Ed. Pg.333.

2. Gaurav Kuthiala, Geeta Chaudhary, pharmacology and clinical use India Mar-April 2011.

3. Birbal Baj,Vandana Tyagi, R.S.Chaudhri, Anand Derashri: A comparative study of effects of clonidine added to ropivacaine versus plain ropivacaine during supraclavicular brachial plexus block. Journal of Evolution of Medical and Dental Sciences 2013; Vol2,Issue 52:10228-10235.

4. El Saied AH, Steyn MP, Ansermino JM. Clonidine prolongs the effect of ropivacaine for axillary brachial plexus blockade. Can J Anaesth 2000 Oct; $47(10): 962-7$

5. Sumanta Ghoshmaulik ,Bikash Bisui,Debasish Saha, Sarbari Swaika,
Clonoidine as an adjuvant in axillary brachial plexus block for below elbow orthopedic surgeries: A comparison between local and systemic administration. 2012, Vol. 6, Issue 2, P. 184-188.

6. Popping DM, Elia N, Marret E,Wenk M; Clonidine as an adjuvant to Local Anaesthetics for Peripheral nerve and Plexus Blocks, A Metaanalysis of Randomised Trials. Anesthesiology,2009;111:406-415

7. Murphy DB et al. Noval analgesia adjuncts for brachial plexus block. A systemic review. Anaesth Analg 2000:2000;1122-1128.

8. David Johnson, Harold Ellis. Pectoral girdle and upper limb.in: Gray"s-The anatomical basis of clinical practice.38th edn. Churchill Livingstone;1999.801-941.

9. Collins Vincent J.Editor. Principles of Anaesthesiology.3rd ed. Philadelphia; Lea and Febiger;1993.

10. Martin Berry, Lawrence H. Bemnister Susan M. Standing "Nervous System”.chapter-8,Gray"s Anatomy,38th Edn,1995;901-1397.

11. Gaurav Kuthiala, Geeta Chaudhary, Ropivacaine: A review of its pharmacology and clinical use. Indian J. Anaesth 2011;55(Issue2): 104-110.

12. Graf BM. The cardiotoxicity of local anaesthetics; The place of ropivacaine. Curr Top Med Chem 2001;1;207-14.

13. Stoelting RK. Local anaesthetics. In: Pharmacology and physiology in anaesthesia practice, 4th edn.2006;p.179-207.

14. Mehdi TRIFA, Sonia Ben Khalifa,Ali Jendoubi, Najeh Zribi, Tarek Regaya, clonidine doesn" $t$ improve quality of ropivacaine axillary brachial plexus block in children.vol.22,issue 5,2012 pg;425-429.

15. Danelli G,Nuzzi M, Salcuni PF, Caberti L,Berti M, Rossini E et al;Does clonidine $50 \mathrm{mcgs}$ improve cervical plexus block obtained with ropivacaine $150 \mathrm{mg}$ for carotid endarterectomy.

16. Casati A, Magistris L, Fanelli G, Beccaria P, Cappelleri G, Aldegheri $\mathrm{G}$ et al; Small dose clonidine prolongs postoperative analgesia after sciatic-femoral nerve block with $0.75 \%$ ropivacaine for foot surgery. Anesth Analg.,2000;91:388-392.

17. Masuki S.Dinenno FA, Joyner MJ, Eisenach JH. Selective Alpha-2 adrenergic properties of dexmedotomidine over clonidine in the human forearm J.Appl Physiol 2005;99:587-92.

18. Butterworth JF, Strichatrz GR. The alpha-2 adrenergic agonists clonidine and guanfacine produce tonic and phasic block of conduction in rat sciatic nerve fibers. Anesth Analog 1993;76:295-301.

19. Singelyn F,Jean-Marie,Annie Robert.A Minimum dose of clonidine added to mepivacaine prolongs the duration of anesthesia and analgesia after Axillary Brachial Plexus Block. Anesth Analg 1996;83:1046-50.

Copyright: ( $)$ the author(s), publisher. Academia Anesthesiologica International is an Official Publication of "Society for Health Care \& Research Development". It is an open-access article distributed under the terms of the Creative Commons Attribution Non-Commercial License, which permits unrestricted non-commercial use, distribution, and reproduction in any medium, provided the original work is properly cited.

How to cite this article: Virupakshamma, Basarigidad A. Adding Clonidine to Ropivacaine in Brachial Plexus Block for Upper Limb Surgeries: Study of Hemodynamic Variables. Acad. Anesthesiol. Int. 2019;4(1):15-18.

DOI: dx.doi.org/10.21276/aan.2019.4.1.4 